\title{
Optical properties of deinked pulp containing thermochromic offset inks
}

\author{
Sonja Jamnicki Hanzer, Marina Vukoje, Matea Zadro Tovernić \\ University of Zagreb, Faculty of Graphic Arts, Zagreb, Croatia \\ *E-mail: sjamnick@grf.hr
}

\begin{abstract}
This paper evaluates the efficiency of thermochromic offset prints recycling using deinking flotation method. Since offset thermochromic inks differ in their composition from conventional offset inks, the aim of this research was to determine how effectively they can be recycled. In the experimental part of the work, the laboratory printing of two thermochromic inks was conducted. For both types of inks, white uncoated paper was used as a substrate. After accelerated aging, the prints were mixed in equal proportions and then recycled in laboratory conditions, by means of deinking flotation. During the recycling process, handsheets and filter pads were prepared from the pulp obtained before and after deinking flotation. Handsheets and filter pads were also prepared from unprinted paper that was used as printing substrate, in order to obtain reference samples. The deinking flotation efficiency was evaluated by calculating the flotation loss, ash elimination, pulp's brightness and whiteness increase and determination of residual ink area. The obtained results indicate that thermochromic prints are poorly deinkable. A small increase in deinked pulp's brightness and whiteness (approx. $7 \%$ and $11 \%$ ) is noticed. The image analysis shows that flotation deinking managed to eliminate around $40 \%$ of the total dirt area of thermochromic ink.
\end{abstract}

Keywords: Thermochromic ink, Deinking flotation, Optical properties, Image analysis

\section{Introduction}

A thermochromic ink is an ink that exhibits colour changes depending on changes in temperature. Thermochromic inks come in two forms: liquid crystals and leuco dyes, with leuco dyes more commonly used in packaging applications. Thermochromic inks based on leuco dyes generally consist of an encapsulated three part system which includes a dye that changes colour, a compound that acts as a colour developer and a solvent. Due to the properties of the dye, the inks are always colourless above a certain temperature and coloured below a certain temperature [1-3]. Each colour has a fixed temperature range and when the required temperature is reached, the colour change takes place, commonly called the activation temperature $\left(\mathrm{T}_{\mathrm{A}}\right)$ or activation point. The change of colour may be irreversible or reversible. Reversible inks go back to a coloured state i.e. the original colour will be restored upon cooling $[4,5]$.
In thermochromic leuco dye-developer-solvent system thermochromic effects are based on changes of absorption caused by molecular interactions of the incorporated functional dye within its microenvironment [6-9]. The thermochromic effect is caused by the formation of leuco dye-developer complexes in a reversible equilibrium redox reaction between leuco dye and developer. The reaction is triggered by interactions between the complex and the solvent during the melting or crystallization process [9]. So at temperatures below the activation point, the solvent is in solid state enabling the dye and colour developer to form a colour, resulting in full colour effect. When the temperature reaches the activation point, the solvent becomes liquid, keeping colour developer and the leuco dye apart [5].

Besides the inks that change from coloured to colourless state when the activation point is reached, thermochromic inks that change from one colour to another are also available 
in the market. This is achieved with an ink that combines a leuco dye with a conventional ink pigment. For example, adding a blue leuco dye to a conventional yellow ink will result in a green ink formulation. In its cool state, the printed ink layer will be green, and once warmed above its activation temperature, it will revert to yellow as the leuco dye becomes clear or translucent [10].

Thermochromic printing inks are a mixture of thermochromic microcapsules dispersed in ink's vehicles. The sizes of microcapsules used in printing inks are in the range of 3 to 5 $\mu \mathrm{m}$ which makes them at least ten times larger than the average size of the colorants used in formulation of conventional printing inks (such as pigments). The main disadvantage of microencapsulated thermochromic systems is their limited lightfastness and the resistance to different atmospheric conditions.

At present, thermochromic printing inks are generally used in "smart packaging", where they are most often employed as indicators of freshness and temperature. They are also very useful in security printing, where they are used on checks, tickets, medication recipes, etc. Recently, such inks are gaining their roles in commercial purposes - decorations, design solutions, promotional materials etc.

Deinking by flotation is the predominant technology used for production of recycled paper and it is of major importance in the production of graphic papers due to the high demand of enhanced optical properties of the finished products [11]. In order to achieve those requirements, improved deinkability of printed paper products has become essential factor. Even though in the past, packaging recovered paper grades were recycled mostly without deinking, lately deinking is also becoming of interest in packaging grades, due to the growing tendency to print certain products such as cartonboard [11-13]. According to Faul (2010) deinking by flotation is highly efficient mostly in the case of conventional offset and gravure printing inks, works well also in case of dry toner prints, but is not efficient enough in the case of UV-cured inks, ink jet and liquid toner inks, as well as in the case of water-based inks [12].

The aim of this study was to evaluate the efficiency of thermochromic offset prints recycling. Considering the fact that thermochromic offset inks differ from conventional offset inks in formulation and size of their colorants due to the presence of the microcapsules that are much larger than conventional pigment particles, it was of interest to check their deinkability behaviour. In our previous study [14], we investigated the deinkability of mixed thermochromic offset prints. There we used offset prints printed with three different inks, obtained from two different manufactures. Those inks differed in the composition of colorants and their vehicles which consequently affected their drying behaviour. In addition to the above mentioned research, there is no available data on the implementation of similar research in the scientific literature.

In this study, we have chosen only one type of commercially available thermochromic offset inks for evaluation of their deinkability behaviour. The inks used in this research were prepared on a vegetable oil basis and were composed of leuco-dye colorants mixed with conventional offset pigments. The efficiency of deinking flotation of thermochromic offset prints is evaluated by calculating the flotation loss, ash elimination, pulp's brightness and whiteness increase and determination of residual ink area.

\section{Materials and methods}

\subsection{Printing substrate}

For the printing of thermochromic offset inks, one white uncoated paper with basis weight of $140 \mathrm{~g} / \mathrm{m}^{2}$ was used as a printing substrate. The characteristics of the used paper are shown in Table 1.

Table 1 Properties of the paper substrate

\begin{tabular}{|c|c|c|c|c|c|c|}
\hline \multicolumn{10}{|c|}{ White uncoated paper } \\
\hline $\begin{array}{c}\text { Basis weight } \\
\left(\mathbf{g} / \mathbf{m}^{2}\right)\end{array}$ & $\begin{array}{c}\text { Thickness } \\
(\mathbf{m m})\end{array}$ & $\begin{array}{c}\text { Bulk } \\
\left(\mathbf{c m}^{\mathbf{3}} / \mathbf{g}\right)\end{array}$ & $\begin{array}{c}\text { Smoothness } \\
(\mathbf{s})\end{array}$ & $\begin{array}{c}\text { CIE Whiteness } \\
(\mathbf{\%})\end{array}$ & $\begin{array}{c}\text { ISO Brightness } \\
(\mathbf{\%})\end{array}$ & $\begin{array}{c}\text { Filler content } \\
(\%)\end{array}$ \\
\hline 140 & 0.159 & 1.14 & 12.3 & 143 & 96 & 31 \\
\hline
\end{tabular}




\subsection{Thermochromic inks}

For the printing of paper samples two leuco dye based thermochromic offset printing inks were used produced by $\mathrm{CTI}^{\circledR}$ (Chromatic Technologies, Inc.), with activation temperatures of $45^{\circ} \mathrm{C}$ for green and $63^{\circ} \mathrm{C}$ for burgundy ink. Both inks were characterized by a reversible colour change. One thermochromic offset ink was coloured in green below its activation temperature $\left(\mathrm{T}_{\mathrm{A}}>45^{\circ} \mathrm{C}\right)$ and above its activation temperature the print changed to yellow (hereinafter GY). Another thermochromic offset ink was coloured in burgundy below its activation temperature $\left(\mathrm{T}_{\mathrm{A}}>63^{\circ} \mathrm{C}\right)$ and coloured to blue when heated above the activation temperature (hereinafter $\mathrm{BB}$ ). The transition from one colour to another was possible because in each of these inks, a microencapsulated thermochromic colorant was dispersed in ink vehicle in combination with another colouring agent, most likely a conventional pigment. The manufacturer's recommendation is to print these inks in a standard offset printing in several layers, in order to achieve satisfactory colour intensity on uncoated papers as recommended printing substrates. These inks are very sensitive to daily light, UV irradiation and atmospheric conditions and it is recommended to be stored at temperatures no higher than $27^{\circ} \mathrm{C}$. Used inks are vegetable oil-based $[15,16]$. Some properties of used thermochromic inks are presented in Table 2.
Table 2 Properties of used thermochromic offset printing inks

\begin{tabular}{|l|l|}
\hline Properties & CTI $^{\circ}$ ink \\
\hline Solid content & $79 \%$ \\
\hline Viscosity & $180-300$ Poise \\
\hline Recommended printing substrate & Uncoated paper \\
\hline
\end{tabular}

The printing trials were carried out using Prüfbau Multipurpose Printability Tester. The quantity of $1.5 \mathrm{~cm}^{3}$ ink was applied on the distribution rollers while printing was performed with the printing force of $600 \mathrm{~N}$. Printing speed was set to $1 \mathrm{~m} / \mathrm{s}$ and printing was carried out with rubber printing forme providing the printing width of $4 \mathrm{~cm}$. All the samples were printed in the full tone (Figure 1). As a result, approximately $74 \%$ of the total area of paper strip was covered with ink.

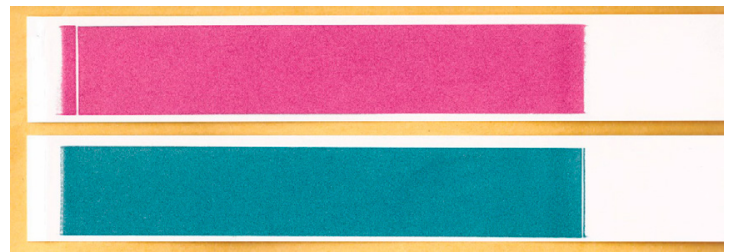

Figure 1 Obtained thermochromic prints

\subsection{Deinking flotation and preparation of handsheets and filter pads}

Flotation deinking of thermochromic prints was conducted in laboratory conditions, according to procedure described in INGEDE method 11p (Figure 2).

Thermochromic offset prints

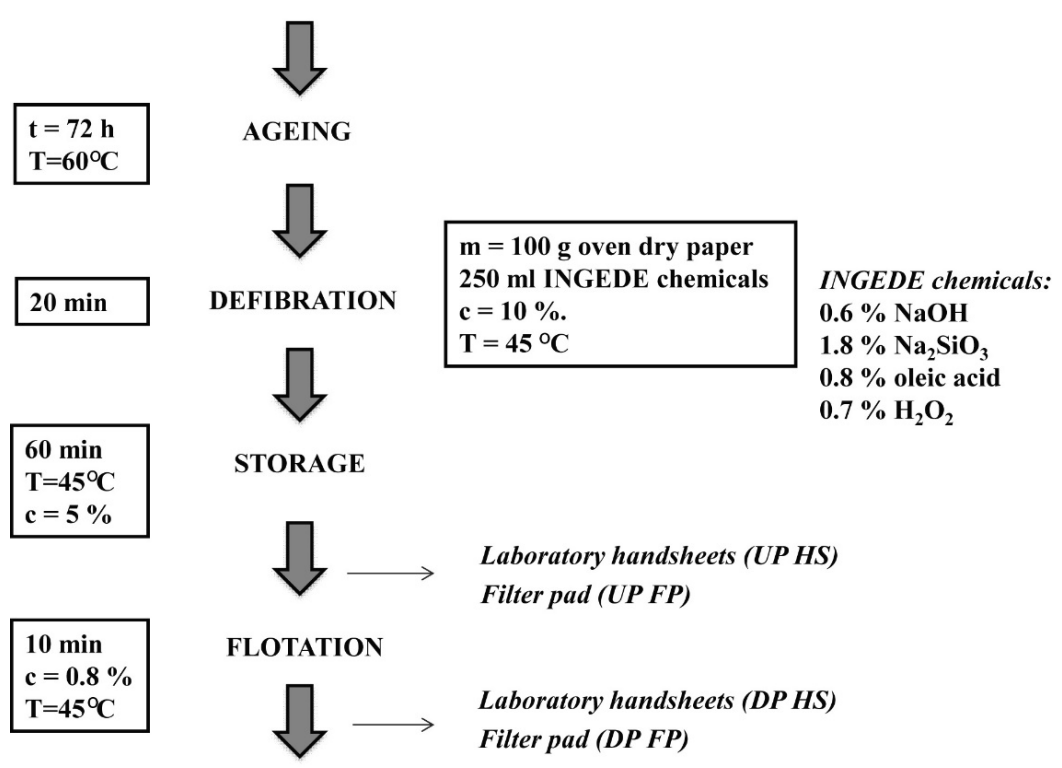

Figure 2 Flow chart of the deinking flotation procedure 
Input material for deinking consisted of two sets of prints which were mixed in equal proportions. To an each printed paper strip one unprinted strip was added in order to avoid the excessive concentration of printing ink in relation to the total mass of paper submitted to deinking. Thus the total area covered by the ink was $37 \%$ when compared to the total area of used paper.

Disintegration of input paper material was conducted in the Enrico Toniolo disintegrator. According to the INGEDE method 1 , a certain amount of suspension was separated in order to make undeinked pulp (UP) handsheets (HS) with a basis weight of $45 \mathrm{~g} / \mathrm{m}^{2}$ and filter pads (FP) with a basis weight of $225 \mathrm{~g} / \mathrm{m}^{2}$. Laboratory paper handsheets were prepared on Rapid-Köthen Sheet Machine, PTI while filter pads were prepared using the Buchner funnel. Flotation process was conducted in laboratory flotation cell. From pulp suspension after flotation, laboratory paper handsheets were prepared (hereinafter referred to as deinked pulp handsheets - DP) and filter pads (FP) were prepared as well. In addition, handsheets and filter pads from blank paper samples were prepared after the pulping of the original unprinted paper (hereinafter referred to as blank samples).

\subsection{Microscopy}

In order to evaluate the presence of microcapsules in thermochromic inks, microscopic images were taken using Olympus BX51 System Microscope. Images were taken under a magnification of $2000 \mathrm{x}$ (Figure 3 ).

\subsection{Determination of flotation loss}

In order to evaluate the effectiveness of flotation deinking, the flotation loss (\%) of the deinking process was determined. Flotation loss is the percent ratio between the amount of oven dry $\left(105^{\circ} \mathrm{C}\right)$ sludge collected during flotation and amount of dried pulp (including filler and ink particles) introduced. It is a very important parameter of flotation deinking because a certain amount of fibres can be lost in rejection stream and froth altogether with ink particles and fillers.

\subsection{Determination of ash content}

Undeinked and deinked pulp filter pads were used for the determination of ash content. For the determination of ash content a test specimen was ignited in a muffle furnace at $525 \pm$ $25^{\circ} \mathrm{C}$ (T $\left.211 \mathrm{om}-02\right)$. The data determined were expressed as the mean of three replicate determinations and presented as mean $\pm \mathrm{SD}$.

\subsection{Determination of optical properties of deinked pulp}

Handsheets and filter pads prepared from undeinked (UP) and deinked (DP) pulps were used for evaluation of their optical properties: ISO Brightness (ISO 2470) and CIE Whiteness (ISO 11475). Brightness is measured as the reflectance of light of an effective wavelength of $457 \mathrm{~nm}$, in the blue region of the spectrum. All measurements were carried out on Konika Minolta CM3600-d Spectrophotometer, according to standard methods. The data determined were expressed as the mean of ten replicate determinations.

\subsection{Determination of cleanliness of deinked pulp}

The analysis of dirt particles of undeinked and deinked pulp is a very important parameter in the evaluation of printed products deinkability [17]. The number of residual ink particles and their total area on handsheets, obtained from undeinked and deinked pulp, were determined by image analysis and data processing, using Spec Scan 2000 (Apogee Systems Inc.) according to ISO 15755. Handsheets were scanned with a resolution of $600 \mathrm{dpi}$. The image was scanned in 256 grayscale mode and for the analysis converted to black and white with manual threshold adjusted on 100, i.e. all pixels under 100 was set to black and above 100 to white. Image analysis was performed on $0.001935 \mathrm{~m}^{2}$ of each handsheet surface to detect particle size distribution. The total number and size of the residual ink particles, as well as their total area was determined.

\section{Results and discussion}

\subsection{Determination of microcapsules}

For the determination of microcapsules and morphology of printed matter, the microscopic images were taken. From the presented Figure 3 it can be seen that printed ink capsules had an average size around $1 \mu \mathrm{m}$ in diameter. 

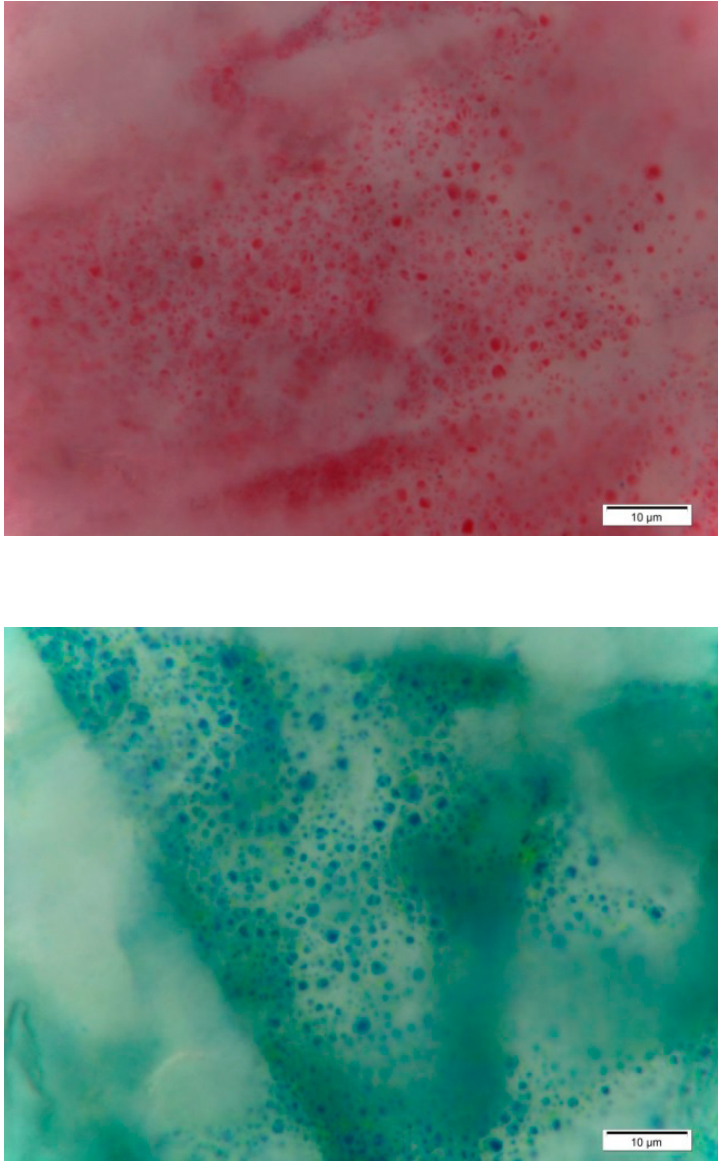

Figure 3 Microscopic image of burgundy-blue (BB) and green-yellow (GY) thermochromic offset prints

\subsection{Flotation loss and ash content elimination}

The flotation loss (\%) of the deinking process is presented in Table 3, as well as the ash content (\%) of tested filter pad samples. From result of ash content determined in froth filter pad $(47.54 \%)$ it is further possible to calculate the total loss of the fibres during the flotation deinking, which is, in this case, quite small amount of only $2.30 \%$. Ash content elimination (\%), calculated from the ash balance of the undeinked and deinked pulp filter pads shows that the ash content was reduced for about $26 \%$ by flotation.

Table 3 Flotation loss and ash content elimination

\begin{tabular}{|l|l|l|}
\hline \multicolumn{2}{|l|}{ Sample } & Value \\
\hline Flotation loss, \% & 4.39 \\
\hline \multirow{2}{*}{ Ash content, \% } & Froth filter pad & $47.54 \pm 2.81$ \\
\cline { 2 - 3 } & UP filter pad & $27.92 \pm 0.27$ \\
\cline { 2 - 3 } & DP filter pad & $20.57 \pm 1.04$ \\
\hline Ash elimination, \% & 26.32 \\
\hline
\end{tabular}

\subsection{ISO Brightness and CIE Whiteness}

Figure 4 shows the results of ISO brightness determinations conducted on handsheets and filter pads of undeinked (UP) and deinked (DP) pulps as well as on the blank samples. For

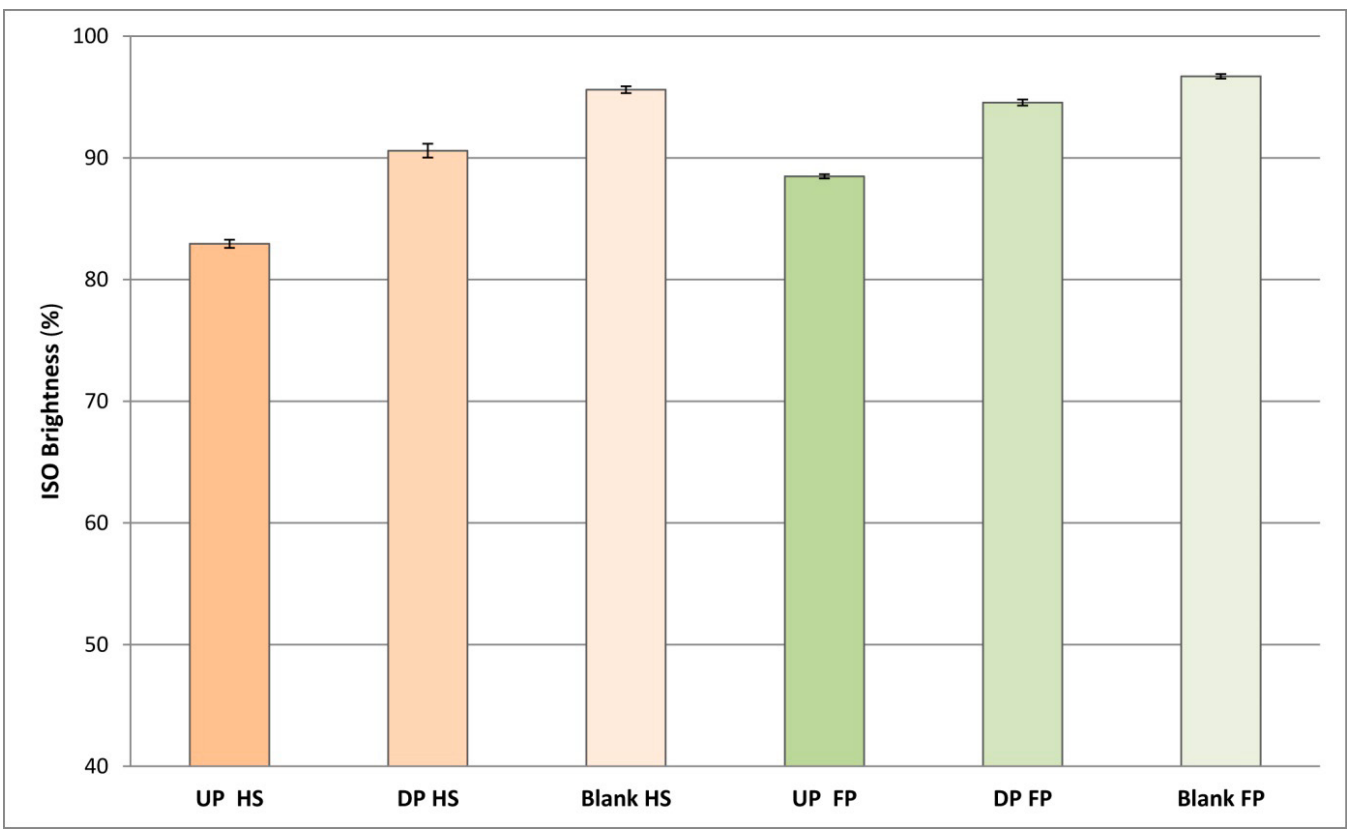

Figure 4 ISO Brightness of blank samples and undeinked (UP) and deinked (DP) pulps (legend: HS -handsheet, FP - filter pad) 


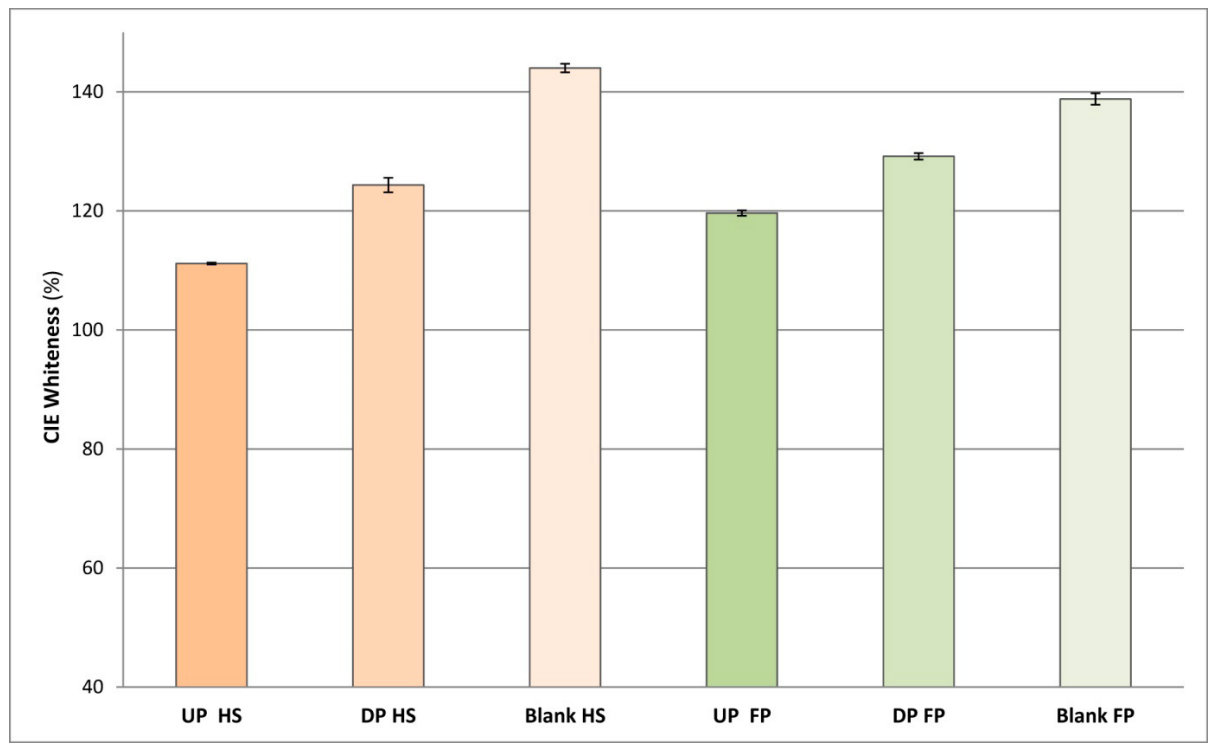

Figure 5 CIE Whiteness of blank samples and undeinked (UP) and deinked (DP) pulps (legend: HS -handsheet, FP - filter pad)

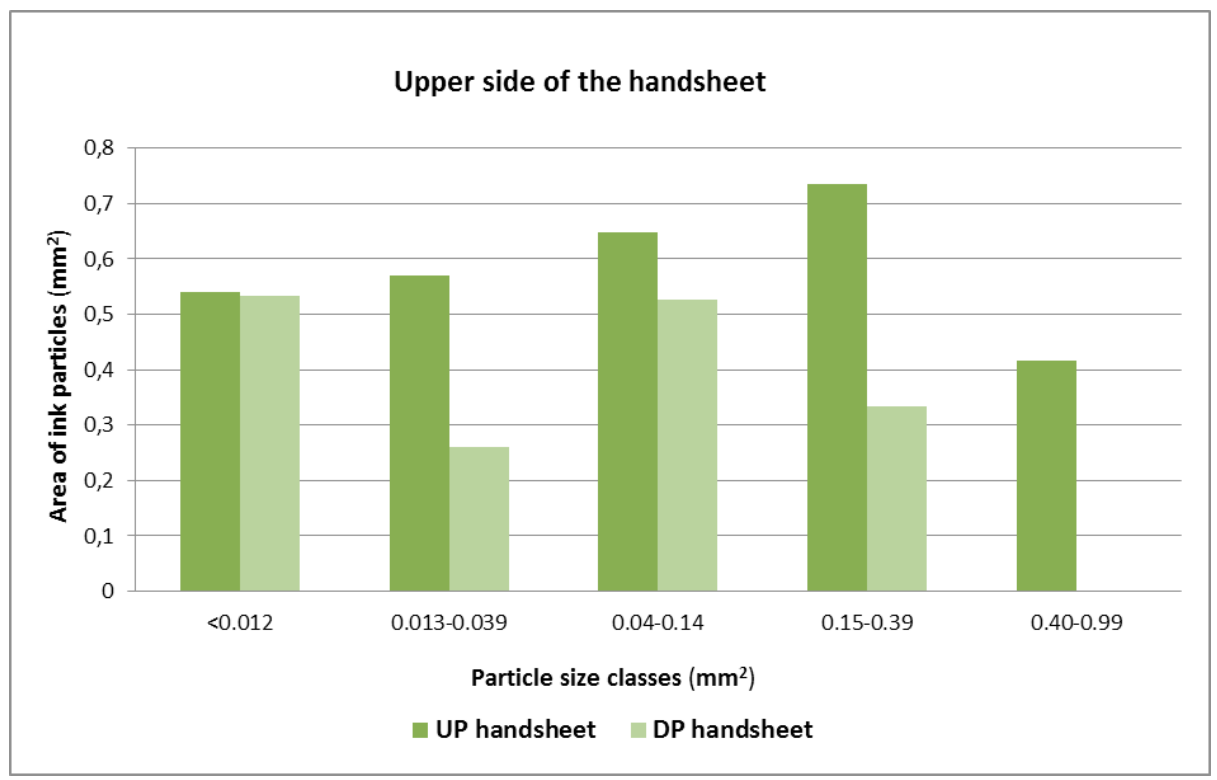

Figure 6 Ink particle size distribution: area of ink particles (ISO 15755) (legend: UP - undeinked pulp, DP - deinked pulp)

each test specimen, ten measurements were performed on the upper side of the handsheets and the filter pads. The results are presented as the arithmetic mean of ten replicate determinations.

Figure 5 shows the CIE Whiteness measurements conducted on handsheets (HS) and filter pads (FP) of undeinked (UP) and deinked (DP) pulps as well as on the blank samples. For each test specimen, ten measurements were performed on the upper side of the handsheets and the filter pads. The results are presented as the arithmetic mean of ten replicate determinations.

The efficiency of deinking process is evaluated through brightness and whiteness increase which is calculated as follows:

$$
\begin{aligned}
& \text { Brightness increase (\%) = DP brightness (\%) - UP brightness (\%) } \\
& \text { Whiteness increase (\%) = DP whiteness (\%) - UP whiteness (\%) }
\end{aligned}
$$


Brightness and whiteness values measured on blank handsheet and filter pad samples are considered to be the pulp's target values (ideally, the level that we want to achieve through deinking).

Results of brightness measurements indicate that flotation managed to improve brightness to some degree, i.e. the brightness increase of $7.7 \%$ and $6.1 \%$ was detected on handsheets and filter pads, respectively (Eq. 1). If the values of deinked pulp's brightness (measured on handsheets) are compared to the brightness target values (observed on blank handsheets) it can be seen that the levels of deinked pulp's brightness deviate from the target brightness values for $5 \%$. Comparing the filter pads in the same manner, a deviation of only $2.1 \%$ is noticed.

The results of CIE Whiteness determination show even greater increase in pulp's whiteness after flotation when compared to brightness increase evaluation. The whiteness increased after flotation for $13.2 \%$ and $9.6 \%$, observed on handsheets and filter pads, respectively (Eq. 2). However, the results show larger deviations from target whiteness values of $19.6 \%$ in case of handsheets and of $9.6 \%$ in case of filter pads.

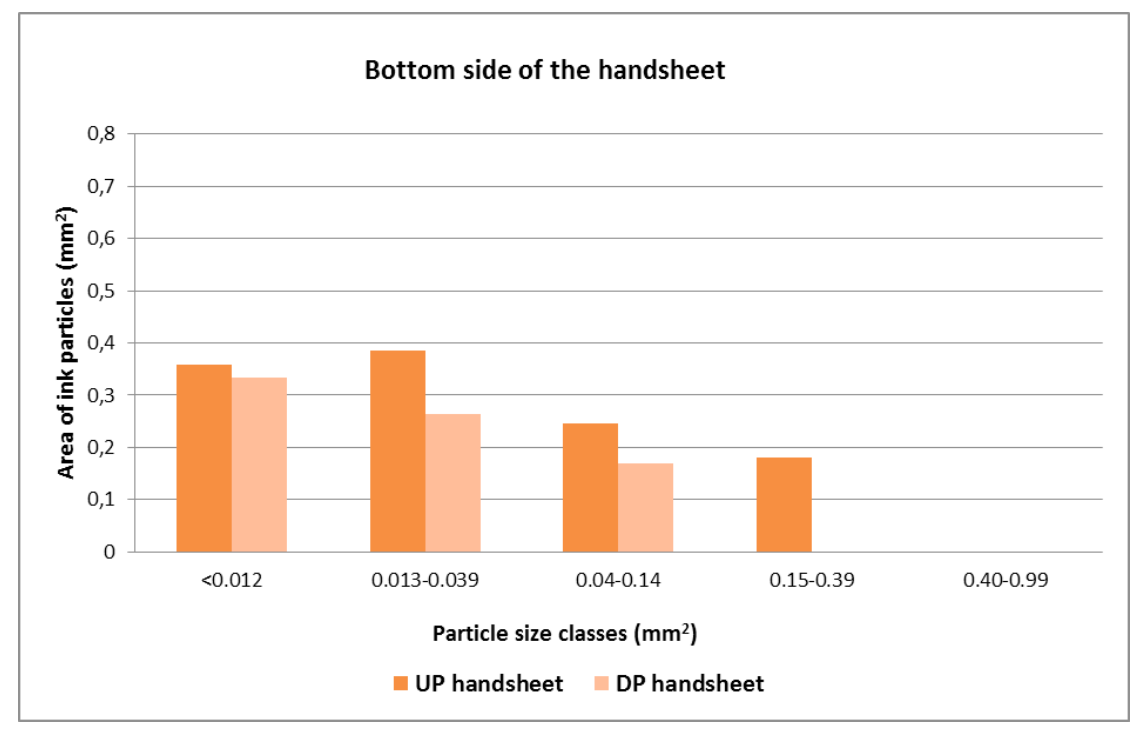

Figure 7 Ink particle size distribution: area of ink particles (ISO 15755) (legend: UP - undeinked pulp, DP- deinked pulp)

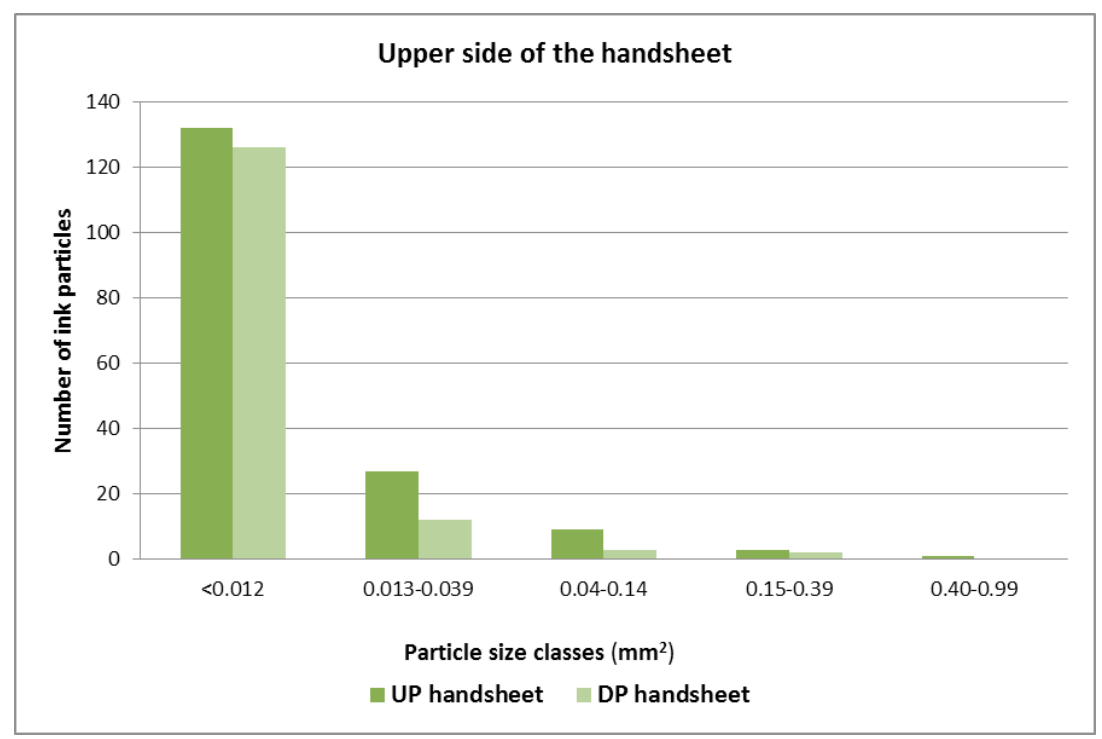

Figure 8 Ink particle size distribution: number of ink particles (ISO 15755) (legend: UP - undeinked pulp, DP - deinked pulp) 


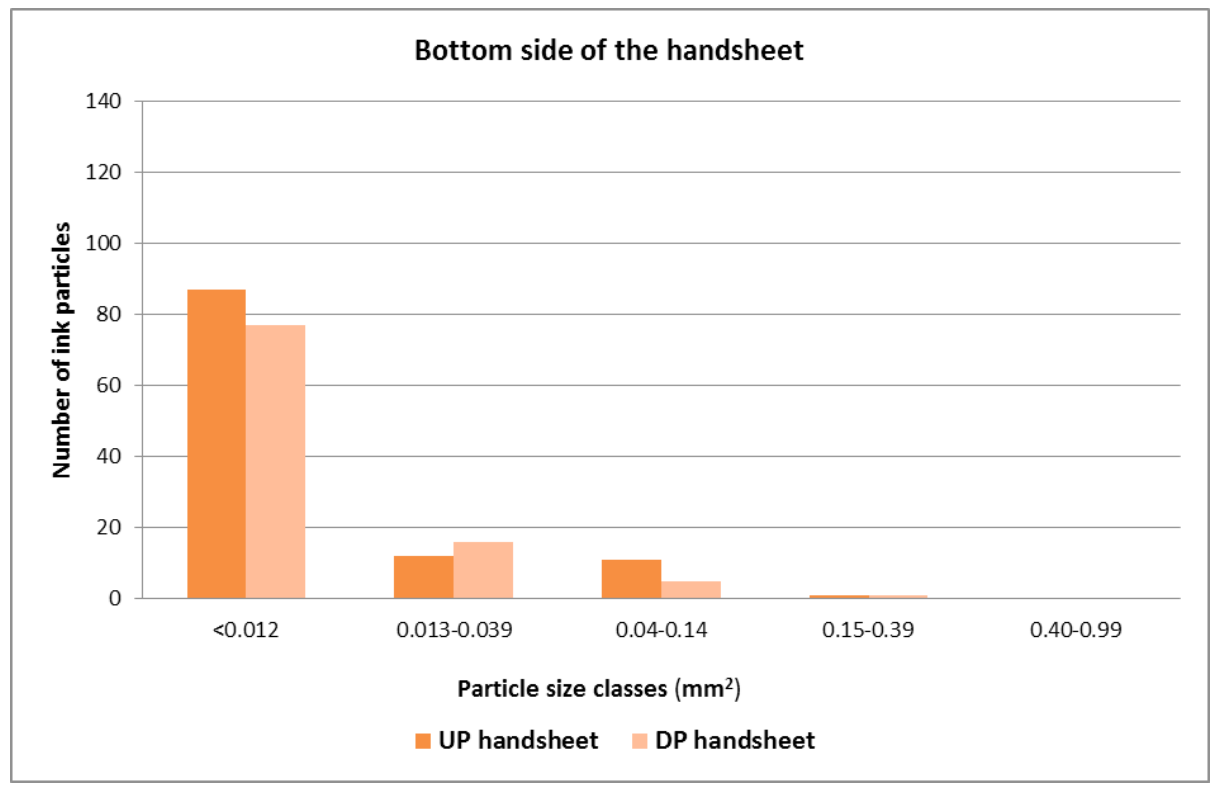

Figure 9 Ink particle size distribution: number of ink particles (ISO 15755) (legend: UP - undeinked pulp, DP - deinked pulp)

\subsection{Cleanliness of deinked pulp}

Figures 6, 7, 8 and 9 show the results of the image analysis. The analysis was carried out on the laboratory handsheets obtained from undeinked and deinked pulp. Three laboratory handsheets were selected, per each specimen, for examination on their upper and bottom sides, and on each side, the analysis was performed on three different places. The results are presented as the arithmetic mean of all conducted measurements, separately for the upper and bottom side of the laboratory handsheets. Figures 6-9 show the number of residual ink particles that are divided into particle size classes (ISO 15755) as well as their total surface area expressed in $\mathrm{mm}^{2}$. Summarized data are presented in Table 4.

Table 4 Image analysis - summarized data

\begin{tabular}{|l|c|c|}
\hline Data & Upper side & Bottom side \\
\hline $\begin{array}{l}\text { Number of ink parti- } \\
\text { cles before flotation }\end{array}$ & 172 & 109 \\
\hline $\begin{array}{l}\text { Number of ink parti- } \\
\text { cles after flotation }\end{array}$ & 146 & 89 \\
\hline $\begin{array}{l}\text { Area of ink particles } \\
{\left[\mathrm{mm}^{2}\right] \text { before flotation }}\end{array}$ & 2.912 & 1.170 \\
\hline $\begin{array}{l}\text { Area of ink particles } \\
{\left[\mathrm{mm}^{2}\right] \text { after flotation }}\end{array}$ & 1.656 & 0.767 \\
\hline
\end{tabular}

The results of the image analysis (Figures 6-9) indicate that there is greater number of ink particles on the upper side of laboratory handsheets which cover larger total surface area compared to the bottom side. This was most likely due to the rinsing of one part of the disintegrated ink particles through the screen when forming a laboratory handsheets. During the recycling process, the ink was disintegrated mainly into very small fragments. The largest number of particles on both, undeinked (UP) and deinked pulp (DP) handsheets, can be found in the particles size class less than 0.012 $\mathrm{mm}^{2}$. In most cases, the number of ink particles after flotation decreases. The results show that deinking flotation reduced the number of disintegrated ink particles smaller than 0.012 $\mathrm{mm}^{2}$ for only $4.6 \%$, and for $11.5 \%$ on upper and bottom side of the handsheets, respectively. Moreover, the class of the smallest ink particles occupies a large area on the handsheets. In addition, it can be noted that very few ink particles are recorded in the class range of $0.04-0.14 \mathrm{~mm}^{2}$ and $0.15-0.39 \mathrm{~mm}^{2}$, but however, they seem to occupy a very large surface area on the handsheets. Nevertheless, most of these larger particles are completely removed by the flotation process. In the overall data of the image analysis (Table 4 ), it can be seen that higher number of ink particles (60-65\%) 
are recorded on the upper side of the handsheet samples and their total surface area is almost twice as large. In addition, it is also visible that deinking flotation managed to reduce the number of ink particles for only $15 \%$ on the upper side of the handsheets and for $18 \%$ on bottom side of the handsheets. A reduction of ink area is also noticed. The total ink area on the upper side of the handsheets decreased for $43 \%$, and for $34 \%$ on the handsheet's bottom side. Obtained results indicate that these inks are poorly deinkable.

\section{Conclusion}

Based on the conducted research, the next conclusion was made. Of all evaluated deinking flotation efficiency parameters, only a flotation loss (4.4\%) and ash reduction by flotation $(26 \%)$ are positively assessed. As far as the optical properties of deinked pulp are concerned, a relatively small increase in pulp's brightness and whiteness properties after flotation indicate the inefficiency of this recycling method for these thermochromic offset inks. In addition, the image analysis further confirmed that deinking flotation was not successful in elimination of disintegrated printing ink particles. It was noticed that the smallest ink fragments (particles) were poorly removed, most likely due to their very small size, which made them difficult to be attached onto the air bubbles during the flotation process, and in that way, removed with the flotation foam from the suspension. For a more efficient recycling process, it may be necessary to devise a new formulation of flotation chemicals and to adjust their concentrations to these specific inks or to apply some other recycling technique such as adsorption deinking.

\section{Acknowledgements}

The authors are grateful for the support of the University of Zagreb, Grant. No. TP122

\section{Refrences}

1. Seeboth A, Lotzsch D. Thermochromic and thermotropic materials. Vol. 1, Taylor and Francis. Boca Raton, FL: CRC Press by Taylor \& Francis Group; 2013. $1-221 \mathrm{p}$.

2. Lam Po Tang S, Stylios GK. An overview of smart technologies for clothing design and engineering. Int J Cloth Sci Technol [Internet]. 2006
Mar;18(2):108-28. Available from: http://www.emeraldinsight.com/doi/10.1108/09556220610645766

3. Bäckman, M. Feasibility study of thermochromic inks for the packaging industry. 2017. Available from: http://lup.lub.lu.se/student-papers/record/8905340

4. Kulčar, R. et al. Colorimetric properties of reversible thermochromic printing inks. Dyes and pigments, 2010, 86.3: 271-277.

5. WRAP. Final report - Background study. „Thermochromic inks and reducing household food waste", UK, 2013. Available from: http://www.wrap.org. uk/sites/files/wrap/Using\%20thermochromic\%20 inks $\% 20$ to $\% 20$ reduce $\% 20$ household $\% 20$ food $\% 20$ waste.pdf

6. Aitken D, Burkinshaw SM, Griffiths J, Towns AD, Ion I. Textile applications of thermochromic systems. Rev Prog Color. 1996;26:1-8.

7. MacLaren DC, White MA. Dye-developer interactions in the crystal violet lactone-lauryl gallate binary system: implications for thermochromism. J Mater Chem [Internet]. 2003;13(7):1695-700. Available from: http://xlink.rsc.org/?DOI=B302249H

8. White MA, LeBlanc M. Thermochromism in Commercial Products. J Chem Educ. 1999;76(9):1201-5.

9. Seeboth A, Klukowska A, Ruhmann R, Lötzsch D. Thermochromic Polymer Materials. Chinese J Polym Sci. 2007;25(2):123-35.

10. Homola, J. (2003): Color-Changing Inks, Brighten your bottom line. Available from: http://www.xslabs. net/color-change/how-stuff-works.htm

11. Blanco A, Miranda R, Monte MC. Extending the limits of paper recycling: Improvements along the paper value chain. For Syst. 2013;22(3):471-83.

12. Faul A. Quality requirements in graphic paper recycling. Cellul Chem Technol [Internet]. 2010;44(10):451-60. Available from: http://www.cellulosechemtechnol.ro/pdf/CCT10(2010)/p.451-460. pdf

13. Jamnicki S, Mikočević ŽB, Stanić M, Lozo B, Muck T. Introduction of Computer Print-outs in the Recycling Process of Printed Folding Box-Board. Progress in Paper Recycling. 2008 Jan 1;18(1):4-8.

14. Vukoje M, Jamnicki S, Rožić M. Deinkability of thermochromic offset inks. Nordic Pulp \& Paper Research Journal, 2016, 31(4): 692-699.

15. Jamnicki Hanzer S, Rožić M, Vukoje M, Jukić M, Galić A, Roži M, et al. Safety Evaluation of Deinked Pulp Containing Offset Thermochromic Inks. Bioresour Technol. 2018;13(1):678-90.

16. Vukoje M, Rožić M, Miljanić S, Pasanec Preprotić S. Biodegradation of thermochromic offset prints. Nordic Pulp \& Paper Research Journal, 2017;32(2):28998.

17. Bobu, E., Ciolacu, F., Cretu, A.: Studies on Neutral Deinking of Different Prints, Proceedings of PTSCTP Deinking Symposium, (2008) Hanecker, E., Galland g. (ed.), pp. 25 1-15, Leipzig, April 2008, PTS-Manuskript: PTS-MS 804, München, 2008 
